\title{
MET NP_000236.2:p.M1250T
}

National Cancer Institute

\section{Source}

National Cancer Institute. MET NP 000236.2:P.M1250T. NCI Thesaurus. Code C162277.

A change in the amino acid residue at position 1250 in the hepatocyte growth factor receptor protein where methionine has been replaced by threonine. 